\title{
A CALIBRAÇÃO DA MORAL PELO POSITIVISMO
}

\section{Lázaro Alves Martins Júnior}

Juiz de Direito da 1 a - Vara da Comarca de Ceres do Tribunal de Justiça do Estado de Goiás. Professor na UniEvangélica - campus Direito de Ceres, Goiás. Doutorando em Direito Constitucional na Faculdade Autônoma de Direito - Fadisp. mag.lamjunior@tjgo.jus.br

\section{Resumo}

A leitura acurada da obra emblemática de Hans Kelsen, Reine Rechtslehre, em sua versão de 1960, traduzida para nosso vernáculo como Teoria Pura do Direito, em uma tentativa de cientificização do estudo jurídico, revela, já naquela edição, sem considerar as mutações conceituais ao longo da carreira do renomado jurista, a perene contemporaneidade e precisão em vários pontos que levam o positivismo a vicejar até hoje como matriz para as teorias mais avançadas de interpretação, dentre eles a relação Moral, Justiça e Direito. Partindo da premissa da relatividade da Moral adotada por Kelsen contraposta às concepções universalistas 0 artigo busca demonstrar que o positivismo resta pujante na tarefa de espancar as contradições comezinhas e definir um quadrante menos sujeito à insegurança jurídica no que tange aos elementos Moral e Justiça.

\section{Palavras-chave:}

Moral. Justiça. Direito. Teoria Pura do Direito. Contemporaneidade. Positivismo.

\section{THE CALIBRATION MORAL ON POSITIVISM}

\section{Abstract:}

Accurate reading of the emblematic work of Hans Kelsen, Reine Rechtslehre in his version 1960, translated into our vernacular as Law of Pure Theory, in an attempt to scientification of legal study reveals, since that issue without considering the conceptual mutations along the renowned jurist career, the perennial contemporaneity and accuracy at various points that lead positivism to thrive today as a matrix for the most advanced theories of interpretation, including the relationship Morality, Justice and Law. Starting from the moral relativity of the premise adopted by Kelsen as opposed to universalist conceptions article seeks to demonstrate that positivism remains vigorous in the task of beating the common contradictions and set a less subject to legal uncertainty quadrant with respect to moral and Justice elements. 


\section{Keywords:}

Moral. Justice. Right. Pure Theory of Law. Contemporaneity. Positivism.

\section{Sumário}

1 Introdução. 2 Moral, Ética e Justiça. 3 Moral Absoluta. Jusnaturalismo. Neopositivismo. 4 Rejeição da Moralidade Absoluta. 5 Contradição Humana. Mito. Exercício do Poder. 6 Kelsen e a Relatividade da Moral, Moralidade Jurídica e sua Contemporaneidade. 7 Evidências do Acerto de Kelsen com a Moralidade Jurídica. 8 Conclusão. 9 Referências. 


\section{INTRODUÇÃO}

A seara das discussões acerca da tríade Moral, Justiça e Direito é permeada pelo náo consenso e numerosas tentativas de argumentação e convencimento geral que perpassam a Filosofia, a Sociologia e os estudos jurídicos.

O conflito de pensamentos pode ser sublinhado por diversos períodos da História, mas talvez tenha seus maiores marcos com as proposiçôes de Imannuel Kant, seguindo-se todo um florescer marcado pela proposta de ideais universais que guiam ou deveriam direcionar a humanidade e sua organização, caminhando, ao menos em parte, como esteio de teses substancialistas e até mesmo dos chamados neopositivismo ou pós-positivismo.

Hans Kelsen, eventualmente divisando em seus diversos estudos a imanente e inevitável contradição humana, a impossibilidade de um consenso absoluto e a volatilidade dos conceitos de Moral e Justiça que influenciavam a aplicação do Direito com a almejada segurança, propôs o estudo da ciência jurídica como reguladora da vida em sociedade, por meio do formalismo, dando vazão às teses procedimentalistas, sugerindo a figura da imputação como resultado da normatividade na condução da vida gregária.

Malgrado Kelsen tenha tido sua obra traduzida para Teoria Pura do Direito e tenha trilhado pela neutralidade política e ideológica em sua proposição de sistema de Direito como ciência e isto tenha gerado situaçóes contraditórias dentro da própria teoria, criando impeditivos à construção de um teorema, v.g., a solução exegética e de aplicação dos conceitos abertos lato sensu, além de ter sido claramente malcompreendida por inúmeros pensadores e reproduzida em críticas levianas ou simplistas até hoje, é absolutamente inequívoco a partir da leitura dos diversos códigos na linha do civil law que a teoria que defendia adquiriu proporçôes mundiais, agregando-se em maior ou menor grau a formalização da maioria dos sistemas jurídicos em vigor sob esta vertente, náo se desvencilhando completamente, comezinhamente, sequer na construção da ordem jurídica sob a tutela das correntes nomeadas como neo ou pós-positivistas.

Nos dias atuais, sob a regência do sistema capitalista em uma dimensão que se materializa em alto grau de desenvolvimento diverso de seus primórdios, o meramente especulativo, a leitura atenta da obra mais famosa de Kelsen contraposta 
à realidade vivida, evidencia que a opção legislativa pela moral jurídica, formal, mesmo que em convívio com uma Moral Absoluta, parente do Jusnaturalismo, sem lindes e controle claro, vicejou em diversos ordenamentos jurídicos, isso se dando também no Brasil.

Sob esta vertente, a partir do estudo de autores que trabalharam a ideia de Moral, Justiça e Direito, este artigo busca demonstrar a percuciente proposta de Kelsen quanto a Moral e Justiça jurídicas, sinalizando que a mesma é aplicada por grande parte da sociedade moderna que vive sob a tutela jurídica do civil law, lastreando o modo de vida atual, material e sobejamente capitalista, ousando o estudo cum grano salis, em apontar similitudes a título ideológico - em vertentes metodológicas opostas - na construção das bases irradiadoras das teses entre o imperativo categórico de Kant e a norma hipotética fundamental de Kelsen.

\section{MORAL, ÉTICA E JUSTIÇA}

É sempre tarefa tormentosa conceituar Moral, Ética e Justiça; os dois primeiros, especialmente, não raramente são tratados como sinônimos (KELSEN, 1998, p. 42; COMPARATO, 2006, p. 25, 27, 39).

Aqui propóe-se, de forma livre, a conceituação de Moral como sendo um conjunto dos sentimentos considerados no cume dos altaneiros e virtuosos vigentes em uma determinada sociedade e em um dado período, que prescinde de positivação e tem atuação sobre o indivíduo internamente e em sociedade, sem olvidar do caráter geral e universalista que alguns lhe imprimam e adiante será abordado; Ética é a Moral selecionada e positivada em digestos específicos direcionados a certas classes ou conjunto de pessoas pertencentes a uma sociedade; e Justiça, é o sentimento de retidáo advinda de uma postura, conduta ou aplicação em determinado caso, normalmente ligada à obediência à Moral vigente na respectiva comunidade gregária, de maior ou menor dimensão (DWORKIN, 2014, p. 122), podendo - ou não - encontrar-se insculpida no diploma como diploma Ético ou no ordenamento jurídico, aí como o Direito, positivado. 


\section{MORAL ABSOLUTA. JUSNATURALISMO. NEOPOSITIVISMO}

Embora o desenvolvimento histórico das Ciências Humanas tenha trabalhado com uma ideia de Moral - ou Ética - natural imperativa desde vetustas épocas com Cícero (COMPARATO, 2006, p. 113), tem-se como marcante a concepção doutrinária kantiana trabalhando o pensamento da existência de uma razão a priori, transcendental - e não transcendente fulcrada em um extremo parâmetro metafísico, como poderia parecer em uma leitura perfunctória - que permearia a conduta ideal da humanidade a partir de um imperativo categórico. G. D. Leoni, no prefácio do festejado livro Crítica da Razão Pura (KANT, 2014, p. 14), sintetiza o entendimento do filósofo de forma percuciente:

A Metafísica, que seria impossível mediante a razão pura teorética, é possível - conforme a filosofia kantiana - mediante a razão prática. A síntese prática a priori está na lei moral, que tem valor absoluto, necessário e universal; e o imperativo da moral não é hipotético, mas categórico: é verdadeiramente moral só aquela ação que prescinde das consequências ulteriores, mesmo que danosas.

Percebe-se assim que Kant rejeitava a ideia de uma relatividade moral. Em épocas mais modernas os princípios kantianos permanecem nas obras de outros autores, rejeitando o esfacelar da ideia do pressuposto de existência de uma Moral Absoluta imperativa que, dentro de sua concepção idealista, deve vicejar como Vontade Geral na consciência e modo de vida humanos (COMPARATO, 2006, p. 230).

Estes pensamentos difundidos e fundidos ao de diversos outros pensadores erigiram a um patamar superior a ideia de valores vigentes fundamentais e absolutos que devem guiar o ordenamento jurídico e, por conseguinte, a humanidade. Comparato, filiando-se a Kelsen (COMPARATO, 2006, p. 361), defendeu que:

$\mathrm{Na}$ verdade, a evolução histórica aponta para a progressiva constituição de uma ordem jurídica superior, fundada nos mesmos valores de respeito integral à dignidade humana, ordem que é o sistema mundial de direitos humanos, o qual se expressa em normas internacionais e nacionais. 
Esta corrente filosófico-jurídica de uma Moral que é precedente ao Direito expandiu-se para vários âmbitos, inclusive o da atuação estatal, mesmo que desvinculada do positivado. O professor Gil César Costa de Paula (2010, p. 29) expóe esta influência no âmbito dos estudos do Direito Administrativo-Constitucional, possibilitando inferir a veia kantiana:

Em sentido lato, administrar é gerir interesses, segundo a lei, a moral e a finalidade dos bens entregues à guarda e conservaçáo alheias. Se os bens e interesses geridos são individuais, realiza-se administração particular; se são da coletividade, realiza-se administração pública.

Embora concebida hoje também no campo do Direito Administrativo-Constitucional, percebe-se claramente na conclusão anterior a dicotomia entre o Direito e a sua faceta elementar da legalidade, e a moralidade, em que esta se posicionaria em um âmbito superior, alinhada aos princípios basilares de toda a Moral e conceitos expostos anteriormente e defendidos deste outrora por Kant e seus seguidores, como dito, aplicáveis universalmente.

Neste diapasão, aparentemente em uma contraposição entre a força jusnaturalística que estes pensamentos impóem e o positivismo que não agrada à natureza humana, sempre dependente de mitos e justificativas para se manter, origina-se o chamado neopositivismo ou pós-positivismo, um amálgama, uma simbiose, dos dois pensamentos que não consegue, como todas as demais concepçóes atuais, encobrir o fato de que o Direito é sempre uma forma de expressão do poder, e a subjetivação da palavra final interpretadora do Direito é um problema sem solução.

Um grande baluarte desta nova expressão e sistema do Direito é o grande jurista e atual ministro do Supremo Tribunal Federal Luis Roberto Barroso que, nos termos adiante transcritos, expóe a validade e vantagem do novo pensamento (BARROSO, 2013, p. 35):

E, assim, supera-se a separação profunda que o positivismo jurídico havia imposto entre o Direito e a Moral, entre o Direito e outros domínios do conhecimento. Para achar a resposta que a norma náo fornece, o Direito precisa se aproximar da filosofia moral - em busca da justiça e de outros valores -, da filosofia política - em busca de legitimidade democrática e da realização de fins 
públicos que promovam o bem comum e, de certa forma, também das ciências sociais aplicadas, como economia, psicologia e sociologia. $\mathrm{O}$ pós-positivismo não retira a importância da lei, mas parte do pressuposto de que o Direito não cabe integralmente na norma jurídica e, mais que isso, que a justiça pode estar além dela.

Nessa perspectiva, percebe-se que mesmo teorias que buscam novas concepçóes e denominaçóes para racionalizar e promover a correção na aplicação do Direito não conseguem se afastar do problema conceitual e do influxo da Moral, que reflete na Justiça. Alexy, com sua teoria estruturante, deixa entrever isso ao perseguir formas matemáticas para obtenção do julgamento ideal. Não obstante, o mesmo autor exprime concordância com a validade da decisão judicial emanada do espectro jurídico, embora eivada de conteúdo ilegítimo sob o prisma da Moral ou Justiça (ALEXY, 2013, p. 213): "Portanto, há razóes para dizer que a falta da pretensão de correçáo de uma decisáo náo a priva necessariamente do seu caráter de decisão judicial válida, mas a torna defeituosa em um sentido relevante não só moralmente".

Na seara da Sociologia, ramo imbrincado com a Filosofia e o Direito, percebe-se também a repercussão da ideia de uma Moral transcendente, universal, possível de ser utilizada como calibrador da aplicaçáo do Direito ou da conduta humana pelas entidades que corporificam o Estado no qual, atendidos os seus comandos, há a promoção do escorreito funcionamento da sociedade. Nestes termos professa Pedro Scuro Neto: “O processo de dar sanção, de confirmar, de aprovar, de ratificar a conduta não se extingue no sistema e na rede de justiça, cuja efetividade depende, em larga margem, de legitimação moral" (2010, p. 142).

É preciso frisar que este estudo não se aprofunda nos conceitos de jusnaturalismo e positivismo, apesar de indigitar aquele como detentor de alguns liames conceituais que se aproximam da concepção da Moral Absoluta e mais tarde auxiliam o movimento do pós-positivismo, vez que este se desgarra do positivismo justamente por uma fórmula interpretativa que supera as lindes formais pautando-se em elementos abstratos, mais próximos da Moral e Justiça. Assim, estes institutos, bem como o Direito Natural, possuem sustentação científica particular e a própria complexidade de suas estruturas permite ilaçóes diversas, inclusive segmentando- 
-os com suas peculiaridades. Herani apud Dimitri Dimoulis expóe em sua obra a perspectiva doutrinária contemporânea de diferenciação dos mesmos (HERANI, 2010, p. 49):

Dimitri Dimoulis (2006, p. 77) propóe uma distinção conceitual em positivismo jurídico lato sensu, distinguindo-o do jusnaturalismo, do direito natural, e positivismo jurídico stricto sensu, diferenciando-o do moralismo jurídico que, em sua opinião, pertence ao positivismo jurídico lato sensu. Dentre os adeptos da categoria stricto sensu expoentes como Austin, Hans Kelsen, Hebert Lionel Adolphs Hart e Joseph Raz, rejeitam não somente o jusnaturalismo, mas também a vinculação do direito a outros fenômenos e sistemas normativos sociais.

Relembrando, diante da complexidade e número ingente de teorias que abordam estes conceitos, que o propósito deste estudo tem âmbito angusto, focado no tema moralidade e Direito, retomando a estes, emerge extreme de dúvidas que vivemos sob o influxo de um ordenamento jurídico pressionado por valores morais e assim humanos e sociais -, tidos definitivamente como controversos e relativos por Kelsen e, por outro lado, passíveis de serem dimensionados em um plano tangível e absoluto e aplicados uniformemente segundo Kant. Assim, repisa-se, formam-se as correntes procedimentalistas, que trabalham com um Direito levado ao ergástulo interpretativo por seu aplicador e abraçam o positivismo, e as substancialistas, que aceitam a interpretação arrimada em princípios e se traduzem nos neologismos neopositivismo ou pós-positivismo, por mais que se recuse, aparentemente com esteios construtivos no jusnaturalismo e no positivismo.

\section{REJEIÇÃO DA MORALIDADE ABSOLUTA}

O pressuposto de uma Moral Absoluta que guie e oriente de forma uniforme a humanidade tem uma dimensáo que não parece racional e empírica, mas, em verdade, metafísica.

O repúdio à Moral instalada em algumas sociedades manifesta-se desde sempre. Nietzsche, iconoclasta e niilista reverberou sobre os valores morais vigentes com arguta contundência (NIETZSCHE, 2009, p. 11-12): 
Este problema do valor da compaixão e da moral da compaixão (- eu sou um adversário do amolecimento moderno dos sentimentos -) à primeira vista parece ser algo isolado, uma interrogação à parte; mas quem neste ponto se detém, quem aqui aprende a questionar, a este sucederá o mesmo que ocorreu a mim - uma perspectiva imensa se abre para ele, uma nova possibilidade dele se apodera como uma vertigem, toda espécie de desconfiança, suspeita e temor salta adiante, cambaleia a crença na moral, em toda moral - por fim, uma nova exigência se faz ouvir. Enunciemo-la, esta nova exigência: necessitamos de uma crítica dos valores morais, o próprio valor desses valores deverá ser colocado em questão - para isso é necessário um conhecimento das condições e circunstâncias nas quais nasceram, sob as quais se desenvolveram e se modificaram (moral como consequência, como sintoma, máscara, tartufice, doença, mal-entendido; mas também moral como causa, medicamento, estimulante, inibição, veneno), um conhecimento tal como até hoje nunca existiu nem foi desejado.

Em Além do Bem e do Mal, o mesmo filósofo retoma a crítica ferrenha a uma única Moral vigente diante da individualidade inerente ao ser humano (NIETZSCHE, 2005, p. 121):

Nenhum desses graves animais de rebanho, de consciência agitada (que propóem defender a causa do egoísmo como causa do bem-estar geral), quer saber e sentir que o "bem-estar geral" não é um ideal, uma meta, uma noção talvez apreensível, mas apenas um vomitório - que o que é justo para um não pode absolutamente ser justo para outro, que a exigência de uma moral para todos é nociva precisamente para os homens elevados, em suma, que existe uma hierarquia entre homem e homem, e, em consequência, entre moral e moral.

Mesmo no discurso do brilhante linguístico e filósofo Noam Chomsky, apontado por alguns como um pacifista ativo - o que ele nega nesta oportunidade -, afere-se a relativização do que é justo e Moral a partir de outros elementos que induzam a uma conduta diversa, difusamente melhor em determinada situação. Em seu debate com Foucault assim se manifestou (CHOMSKY, 2014, p. 67):

...não sou pacifista engajado. Não defenderia que, sob quaisquer condições imagináveis, fosse errado usar a violência, muito embora esse uso seja, em certo sentido, injusto. 
Mas o uso da violência e a criação de algum grau de injustiça só podem ser justificados com base na alegação e na avaliação - que sempre deve ser feita de maneira muito, muito séria e com uma boa dose de ceticismo - de que essa violência está sendo exercida porque se alcançará um resultado mais justo. Sem tal fundamento, na minha opinião, ela é, de fato, totalmente imoral.

Náo obstante a antiguidade dos pensamentos com supedâneo na Moral Absoluta anteriormente expostos, ressonantes também em Durkheim (FERREIRA, 2012, p. 47; ARON, 2008, p. 549-550), A. L. Machado Neto (1987, p. 174), Cesare Beccaria (2014, p. 16) e outros autores, o processo de miscigenação dos povos e culturas não levou a uma uniformização, a uma Moral global.

Esta conclusão não se escuda sob o pálio de maior ou menor densidade democrática ou evolução social de um Estado ou sua apostasia ou natureza laica.

A título de paradigma para reflexão, a maior democracia mundial, inclusive no âmbito religioso, a estadunidense, contempla em seu cabedal jurídico a possibilidade de aplicação da pena capital aos seus cidadáos. Estados ditatoriais, fundamentalistas e teocráticos também. Destoam eventualmente na forma de se processar e nas características de seus julgamentos e órgãos julgadores, mas em nada diferem no resultado.

Eclode assim que a relativização da Moral é, como em tempos passados, fruto das concepções gregárias formadas, ou seja, culturas e desenvolvimentos díspares, bem como da subjetividade que leva o indivíduo, inclusive, a arrostar o que se encontra positivado juridicamente ou moralmente - caso não positivado e apenas assentado no consciente com potencial consenso -, gerando as condutas desviantes (DIAS, 2014, p. 129, 156), muitas vezes móvel das mudanças de arquétipos - nem sempre saudáveis - instalados em um determinado corpo social. Aqui reside a inevitável e perene contradição humana.

Esta descoberta permite pensar que o domínio da Moral e do Direito e como estes são utilizados está ligado ao Poder e seu exercício, mesmo que sob o mote de pacificação social. Reinaldo Dias apresenta escólio sobre esta neutralidade moral do Direito moderno (DIAS, 2014, p. 146-147): 
Atualmente, na maioria das sociedades existentes, desapareceu tanto a unidade religiosa, como também a unidade ética; generalizou-se o pluralismo moral. Esse fato tem favorecido a tendência do Direito em procurar a neutralidade diante dos diferentes códigos morais, procurando cumprir sua função fundamental de unir e pacificar as relações sociais.

A neutralidade moral no texto legal positivado deixa à mercê do intérprete optar pela Moral mais adequada, aqui sob a perspectiva da relatividade da Moral, e aqui se apresenta o risco que deve ser minimizado e mais bem estudado; também resta empiricamente rejeitada a ideia de uma Moral Absoluta precedente e validadora do Direito positivado, construção intelectual de oposição que pode ter partido da cristalização da percepção de que o Direito, verdadeiramente, é instrumento de Poder, de dominação, possivelmente o mais agressivo da História humana.

Diante deste contexto, apresenta-se lapidar e vigente o repúdio de Kelsen ao elemento da Moral Absoluta como legitimador da validade do Direito como expressão de poder estatal, merecendo a transcrição de seu ensinamento (KELSEN, 1998, p. 47):

Por tal forma, pois, não se aceita de modo algum a teoria de que o Direito, por essência, representa um mínimo moral, que uma ordem coercitiva, para poder ser considerada como Direito, tem de satisfazer uma exigência moral mínima. Com esta exigência, na verdade, pressupóe-se uma Moral absoluta, determinada quanto ao conteúdo, ou, entáo, um conteúdo comum a todos os sistemas de Moral positiva.

Desenha-se assim com matiz extremamente tenaz e desbotada do colorido excessivamente otimista perseguido por Kant, a real relação do Direito e sociedade, bem como desta com o Poder, contendo-se a Moral em perspectiva extra ou intra legal a partir do convencionado institucionalmente em um Estado por meio da atividade política, expressão de interesses e dominação que se condensa no texto legal.

É importante frisar que a percepção esboçada neste trabalho é de que Kelsen traçou sua teoria com base no que apreendeu como a realidade das relaçóes humanas e o que lhe pareceu mais pertinente para viabilizar um sistema jurídico, com uma 
calibração da Moral e Justiça pelo positivismo, não promovendo a refutação das ideias kantianas, tão somente dispensava o mínimo moral como elemento obrigatório de validade do Direito.

\section{CONTRADIÇÃO HUMANA. MITO. EXERCÍCIO DO PODER}

A contradição humana que impede um consenso absoluto, levando-se em consideração aqui o que revelam os estudos sobre o agir comunicativo de Habermas em sua Teoria Consensual, que se contentava com o consenso potencial a partir de um consenso fundado ou fundamentado criado pela força do discurso e do argumento (ALEXY, 2013, p. 117-119), impende presumir que Kelsen, estudioso de variadas cepas, transitando pela Psicanálise e Ciências Naturais, demonstrou nas Ciências Humanas e especialmente nas Jurídicas, formidável tirocínio, e se apercebeu da impossibilidade de traduzir para um sistema de controle social a insegurança de uma - ou várias - Moral, abstrata e susceptível de usurpação pelo exercente do poder.

A humanidade sempre se arrimou no Mito para sua própria sobrevivência, curta, etérea e possivelmente vazia se não preenchida por crenças que o façam colmatar a lacuna existencial e reprimir os desejos e afastar o medo, elementos da vida coletiva (GUERRA FILHO; CARNIO, 2016, p. 25).

Nietzsche disse que "Todo o âmbito da moral e da religião se inclui nessa noção de causas imaginárias - "Explicaçâao" das sensaçôes gerais desagradáveis" (NIETZSCHE, 2015, p. 55). Complementa mais adiante na mesma obra que: Onde a fé é necessária. - Nada é mais raro entre moralistas e santos do que a retidão; talvez eles digam o contrário, talvez até acreditem no contrário (p. 105). São expressôes que revelam a necessidade do homem de crer em algo para dar vazão à continuidade existencial permeada de inconsistência, contradiçôes e desigualdades, sob pena de, inexistindo o Mito, fenecer a sociedade e seu desenvolvimento até aqui. Norberto Bobbio trilha pensamento semelhante fazendo borbotar a imagem do Mito Religião quando declara (2004, p. 51):

O que nós chamamos de "consciência moral", sobretudo em função da grande (para não dizer exclusiva) influência que teve a educaçáo cristá na formação do homem europeu, é algo relacionado com a formaçáo e o crescimento da 
consciência do estado de sofrimento, de indigência, de penúria, de miséria, ou mais geralmente, de infelicidade, em que se encontra o homem no mundo, bem como ao sentimento da insuportabilidade de tal estado.

Indubitavelmente a religião, acompanhada dos costumes criados geraram os primeiros condicionadores sociais - e Mitos - que possibilitavam aos indivíduos perpassar suas contradiçóes contendo-se entre suas pulsóes - ou desejos - e o medo, evoluindo posteriormente este condicionador - e Mito - para os tempos modernos na pessoa do Estado que se manifesta solidamente por meio do Direito.

Percebe-se a existência do Mito na pessoa do Estado, ocasionalmente e não raro traduzido no governante que o personificava, aqui sem rigor científico, já em priscas eras, por exemplo, na passagem do livro A Arte da Guerra, quando se lê que "A Lei Moral é aquilo que deixa as pessoas em completa consonância com seu lider, a ponto de fazer com que o sigam a despeito da própria sobrevivência, a despeito de qualquer perigo" (TZU, 2011, p. 17). A Moral aqui, como em outras perspectivas, está em harmonia com a Lei, entretanto, passando esta pelo filtro que transmuta os anseios populares ou do tirano, no conteúdo legal. Há, aparentemente desde sempre, uma adequação do que é Moral por quem lidera - ou domina - os povos.

Este vetor condicionador brutal do ser humano e viabilizador do Poder, o Direito, por ser fruto de contradiçóes e servir para espantar - ou espancar os que provocam - o dissenso e pacificar o seio social, sempre acaba por encontrar arautos opositores que defendem conteúdos morais não contemplados no texto positivado, justamente por entenderem que existem situaçóes iníquas, e embora estas manifestaçóes contrárias não possam ser traduzidas em consenso, sentimento geral ou vontade absolutas, não devam ser solenemente desprezadas diante das alteraçóes de concepçôes nos corpos sociais.

A verdade é que o Direito, moral ou náo sob a perspectiva kantiana, não conduz a mudança efetiva dos sentimentos, condutas e peculiaridades físicas e mentais dos cidadãos a ele submetidos. Schopenhauer, em alguns momentos inspirador de Nietzsche, afirmava que (SCHOPENHAUER, 2014, p. 103): 
A virtude, assim como o gênio, não se ensina; a ideia que se faz da virtude é estéril, e só pode servir de instrumento, como as coisas técnicas em matéria de arte. Esperar que os nossos sistemas de moral e as nossas éticas possam tornar os homens virtuosos, nobres e santos é tão insensato como imaginar que os nossos tratados sobre estética possam produzir poetas, escultores, pintores e músicos.

Deve-se ainda atentar para as pulsóes que se alinham convenientemente ao que foi positivado independente do conteúdo moral vigente. Não é incomum os interesses egoísticos sobreporem-se ao que se considera relevante moralmente em consenso potencial. Zygmunt Bauman em sua obra Aprendendo a Pensar com a Sociologia discorre sobre a tensão entre o indivíduo e seus interesses e o dever moral (BAUMAN, 2010b, p. 123-124):

A autopreservação e o dever moral frequentemente se encontram em tensão. Um não pode reivindicar ser mais "natural" que o outro, isto é, mais bem sintonizado com a predisposição inerente à natureza humana. (...) Motivações interesseiras ou morais tornam-se predominantes dependendo das circunstâncias sobre as quais as pessoas assim orientadas podem ter controle apenas limitado.

No mesmo diapasão escreveu Cesare Beccaria (2014, p. 16):

Ninguém faz graciosamente o sacrifício de uma parte de sua liberdade apenas visando o bem público. Tais fantasias apenas existem nos romances. Cada homem somente por interesses pessoais está ligado às diversas combinaçôes políticas deste globo; e cada um desejaria, se possível, não estar preso pelas convenções que obrigam os demais homens.

Após esta tessitura de elementos trazidos à baila é possível afirmar que o discurso desenvolvido historicamente de observância pelo Direito de um obrigatório conteúdo Moral, partindo de uma Moral Absoluta, está atrelado ao idealismo isolado que irradia o pensamento crítico de uma parcela da sociedade, bem como a hipocrisia institucionalizada, como divisou Nietzsche em Assim Falava Zaratrusta ao descrever o agir amoral de 86\% das pessoas adultas (NIETZSCHE, 2012, p. 15-16). 
Trata-se o Direito, verdadeiramente, independentemente de seu conteúdo, do exercício do Poder a partir do que se condiciona em uma sociedade e, parafraseando Machado de Assis, as leis náo mudam a sociedade, e sim o inverso, e aquela, a sociedade, é o ninho das contradiçôes e das relaçóes de dominação e submissão, gerando morais diversas.

Recorre-se novamente a Nietzsche para corroborar este pensamento (2005, p. 75):

O que os filósofos denominavam "fundamentação moral", exigindo-a de si, era apenas vista à luz adequada, uma forma erudita da ingênua fé na moral dominante, um novo modo de expressá-la, e portanto um fato no interior de uma determinada moralidade, e até mesmo, em última instância, uma espécie de negação de que fosse lícito ver essa moral como um problema - em todo o caso o oposto de um exame, questionamento, análise, vivissecção dessa mesma fé.

Aplicando ao Direito um conteúdo moral dominante, admite-se a relatividade da Moral, como defendeu Kelsen. Aceita-se ainda a sua mudança de acordo com a ideologia dominante que, raramente, é a da maioria dominada pela sua seletiva exclusão do comando dos instrumentos que se imiscuem na opinião pública, com ingerência decisiva. Reforça este ponto de vista a relevante lição de Aron acerca do domínio das concepçóes capitalistas na sociedade (ARON, 2008, p. 780):

Hoje, já não há necessidade de motivação metafísica ou moral para que os indivíduos se conformem com a lei do capitalismo. (...) Hoje pouco nos importa saber se o indivíduo que se encontra diante de uma grande sociedade industrial é católico, protestante ou judeu; se é luterano ou calvinista; se vê uma relação entre seu êxito econômico e as promessas de salvação.

Destarte, existindo, desde sempre, aqueles incumbidos de ditar ou propor com força persuasiva o que era Moral e posteriormente passível de ser Direito, temos que de forma subjacente existe uma relação de Poder advinda do exercício político. No livro Teoria Política do Direito - A Expansão Política do Direito, Willis Santiago Guerra Filho e Henrique Garbellini Carnio expressam a possibilidade de cientificizaçáo da política, divisando-a da Moral, semelhante a proposta de Kelsen envolvendo o Direito e a moral (GUERRA FILHO; CARNIO, 2013, p. 15): 
Se, na Antiguidade, o discurso, a moral e a política encontram-se indissociavelmente ligados, nessa época, dita moderna, vai se caracterizar, dentre outras coisas, pela desvinculação que se opera entre elas, no discurso agora não mais político (e moral), mas sim científico, sobre a política e o que lhe é mais próprio: o poder.

Assentindo com a relação de dominação e poder, o segundo autor anteriormente citado discorre em outra obra, com elementos trazidos da Filosofia de Nietzsche, a perspectiva da imanente desigualdade humana que resulta neste binômio (CARNIO, 2013, p. 162):

Justamente nesse sentido se compreende a intensa crítica nietzschiana sobre a moderna doutrina de igualdade de direitos. Se a própria noção de direito se estabelece na pretensão de regularização e ação social fundada no reconhecimento de vários graus de poder que vigem entre os homens, é preciso então que a desigualdade seja pensada como uma das próprias condiçóes para que haja direitos, pois a suposição ideal de uma sociedade universal é no mínimo irrazoável ao passo em que o mundo é formado por relaçóes de dominação e poder.

Pelo exposto, as proposiçóes de Kelsen na Teoria Pura do Direito no que se refere à Moral e ao Direito, mostram-se perfeitamente alinhadas com a tentativa de submeter o Direito, como ciência e instrumento de exercício do Poder, dentro de linhas estatais mais modernas e menos ditatoriais, a um escrutínio potencialmente popular e com estreita dimensão para manipulação pela Política, visando a uma maior segurança jurídica e verdadeiro reflexo positivado do sentimento predominante no povo; em momento algum defendeu a amoralidade material do Direito, mas sim sua identidade com o ideal majoritário do corpo social ao qual se dirigia, uma vez que a sua fragilidade formal ou interpretativa dá azo às manipulaçóes emanadas pela busca de poder, ínsitas no ser humano dotado de desejos e dominado pelas contradiçóes.

\section{KELSEN E A RELATIVIDADE DA MORAL, MORALIDADE JURÍDICA E SUA CONTEMPORANEIDADE}

Kelsen defendeu que "Na medida em que a Justiça é uma exigência da Moral, na relação entre a Moral e o Direito está contida a relação entre a Justiça e o Direito" (1998, p. 42). Desta assertiva passa-se a outras duas que dão a dimensão exata do 
que significavam para Kelsen, dentro de sua teoria, os conceitos de Justo e Moral: "Como categoria moral, direito significa o mesmo que justiça." e "Justo', aqui, é meramente outra palavra para “juridico'” (KELSEN, 2013, p. 78).

Sintetizando, para Kelsen, o que seria Moral ou Justo seria definido pelo corpo social por intermédio de seus representantes e o processo legislativo previamente definido, transmutando-se na lei positivada, partindo daí uma decisão válida e legítima independente do conteúdo Moral. Esta delinearia, sem grandes possibilidades de percalços interpretativos, o que devia ser considerado Justo e Moral, o que se mostra diametralmente oposto à ideia kantiana de uma Moral subjacente e universal que deve permear todas as açóes humanas, inclusive a criação do direito positivo.

Esta fórmula de construção legislativa positivada, em tese, dificultaria as inserçóes políticas na interpretação de forma a tornar o que o povo considerou moral em imoral ou justo em injusto e, absolutamente, em nenhum momento significou a defesa de um Direito amoral ou injusto. Extrai-se de sua obra o seguinte trecho que promove a ablação de dúvidas com relação a isso (KELSEN, 1998, p. 45):

A questão, porém, é também respondida no sentido de que o Direito pode ser moral - no sentido acabado de referir, isto é, justo -, mas não tem necessariamente de o ser; que uma ordem social que não é moral, ou seja, justa, pode, no entanto, ser Direito, se bem que se admita a exigência de que o Direito deve ser moral, isto é, deve ser justo.

Destarte, não existiu a defesa de um direito injusto ou imoral por Kelsen. $\mathrm{O}$ que ele buscou foi criar um quadrante sistemático compreendendo um sistema jurídico a ser preenchido pelo conteúdo valorado pelas respectivas sociedades, tornando o estudo deste arquétipo sistemático (e não seu conteúdo) uma ciência. Isso fica patente em outro de seus trechos sobre a relatividade da justiça (KELSEN, 1998, p. 47-48):

Uma teoria dos valores relativista não significa - como muitas vezes erroneamente se entende - que não haja qualquer valor e, especialmente, que não haja qualquer Justiça. Significa, sim, que não há valores absolutos mas apenas valores relativos, que não existe uma Justiça absoluta mas apenas uma Justiça 
relativa, que os valores que nós constituímos através dos nossos atos produtores de normas e pomos na base dos nossos juízos de valor não podem apresentar-se com a pretensão de excluir a possibilidade de valores opostos.

A leitura acurada do discurso de Kelsen acerca da Moral em sua comentada obra faz-nos ver que argutamente este tratou da contradição humana e o eterno dissenso, buscando uma metodologia científica no âmbito da regulamentação das leis positivadas para, sem evitar de forma inquebrantável a subjetivação do intérprete, minimizar a instabilidade provocada pela divergência advinda dos valores morais, quiçá sempre relativos, tratando Moral e Justiça como símiles e as contendo nas lindes do Direito Positivado.

Flui destas observações que Kelsen teve um propósito altaneiro e virtuoso.

Da mesma forma, parece ter divisado o fenômeno político e o exercício do Poder e sua atuação sobre o corpo social, perscrutando e entendendo de forma ímpar o funcionamento do sistema estatal, tanto que seus pensamentos defendidos mostram-se vigentes até hoje em diversos ordenamentos jurídicos.

\section{EVIDÊNCIAS DO ACERTO DE KELSEN COM A MORALIDADE JURÍDICA}

Um estudo mais detido dos ordenamentos jurídicos em vigência revela o acerto e a perspicácia de Kelsen ao tratar da relatividade de Moral e Justiça e defini-las juridicamente, no seu contexto, positivamente.

Convivemos com o positivismo, cerne até mesmo para o pós-positivismo que dele não se desgarra totalmente, entretanto nos deparamos com situações de inequívoca fricção entre legalidade e moralidade quando se adota a criação kantiana atualmente canalizada no substancialismo e suas vertentes após o positivismo.

Um exemplo clássico desta intermitente colisão está na concepção de defesa técnica do réu e seu conteúdo. 
Criou-se de forma robustamente espraiada pelo mundo contemporâneo a necessidade da defesa efetiva do acusado de ter praticado conduta antijurídica na esfera criminal. O pressuposto para erigir esta defesa como pilar de sustentação de uma real defesa tem como fito - sua justificação moral e filosófica - que ao final se chegue à aplicação de uma pena justa, com apoio na verdade real.

Para tanto, o parágrafo $2^{\circ}$ do artigo $2^{\circ}$ da Lei no 8.906 , de 4 de julho de 1994, diz que "No processo judicial, o advogado contribui, na postulação de decisão favorável ao seu constituinte, ao convencimento do julgador, e seus atos constituem múnus público". O inciso LXIII do artigo $5^{\circ}$ da Constituição da República Federativa do Brasil preconiza que "o preso será informado de seus direitos, entre os quais o de permanecer calado, sendo-lhe assegurada a assistência da familia e de advogado."

Em nossos tribunais não são incomuns as decisóes de anulação de sentenças considerando o réu indefeso quando o causídico confessa a autoria e pugna a aplicação da pena em seu mínimo legal. Transcrevo:

E DE ANULAR-SE O PROCESSO QUANDO O RÉU FICOU INDEFESO, JÁ QUE SEU DEFENSOR, NAS OPORTUNIDADES LEGAIS QUE LHE FORAM ASSEGURADAS, NÃO FOI APENAS OMISSO, MAS ADMITIU A PROCEDÊNCIA DA ACUSAÇÃO. RECURSO HABEAS CORPUS CONHECIDO E PROVIDO PARA QUE O RÉU SEJA SUBMETIDO A NOSSO JULGAMENTO. (RHC 54906, Relator(a): Min. CORDEIRO GUERRA, Tribunal Pleno, julgado em 18/11/1976, DJ 31-12-1976 PP-11240 EMENT VOL-01047-08 PP-01876)

APELAÇÃO CRIMINAL. ROUBO QUALIFICADO E TENTATIVA DE ROUBO. ALEGAÇÓES FINAIS DA DEFESA. RÉU INDEFESO. NULIDADE. 1) É de se ter por indefeso o réu quando o defensor dativo, ao apresentar as derradeiras alegaçóes, limita-se a concordar com o sujeito acusação requerendo a condenação do acusado. 2) A ausência de argumentos em favor do réu viola o princípio constitucional da ampla defesa. A Constituição Federal por seu artigo $5^{\circ}$, inciso $\mathrm{LV}$, assegura às partes igualdade de tratamento. 3) Nulidade do processo decretada ex offício, a partir das alegaçôes finais da defesa, inclusive. Prejudicado o exame de mérito (2015). 
A positivação legal exige do profissional da advocacia que crie teses que possam favorecer seu cliente, sendo isso totalmente despido da estrita observância ao principio da verdade real que regeria o processo penal e eventualmente choca-se com os princípios da ampla defesa e liberdade, e dentro desta colisão axiológica, prestigia-se a que se alinha com a interpretação substancialista, moral e principiológica.

A lei em sua estrita leitura considera moral atuar de forma mendaz, com argumentos inverossímeis ou criar subterfúgios legais para que o acusado escape à aplicação das sançôes, não sendo imoral, legalmente, que o defensor receba lautos honorários e tenha plena consciência da culpa de seu constituinte. A lei estipula apenas que o causídico deve conseguir uma decisáo favorável ao seu cliente.

Não se trata aqui de crítica aos profissionais da advocacia ou à Moral Jurídica estabelecida nos dispositivos antes transcritos em clara prescrição adequada à hipótese kelseniana, mas somente um exemplo de como o Direito Positivado pode trazer substrato para conferir moralidade à conduta - por muitos vista como imoral ou injusta -, nos exatos termos do que Hans Kelsen alinhavou em sua Teoria Pura do Direito na edição aqui referida.

Em suma, a sociedade, a partir dos valores que lhe são caros, estipula o que é moral e justo - embora estes conceitos possam ser construídos de maneira não acendrada -, e vivemos, como dizia Kelsen, à luz de uma Justiça e Moral jurídicas calibradas positivamente na lei, mesmo que atualmente em uma menor dimensão de importância no sistema jurídico.

\section{CONCLUSÃO}

Como sintetiza Reinaldo Dias, "Nem a moral, nem o chamado Direito natural são fontes formais do Direito positivo, mas sim de sua justificação. Não há outro Direito que o positivo. Todo Direito é ou foi positivo" (DIAS, 2014, p. 136).

Partindo de teses com pretensáo de se constituírem em teoremas, Kant, com o imperativo categórico e Kelsen com a norma hipotética fundamental, guardadas as devidas proporçôes e pretensóes, tiveram propostas parecidas do ponto de vista ideológico a partir de suas matrizes. Kant buscava uma lei universal com característica fundante para a Moral, aplicável de maneira linear ao ser humano; 
Kelsen, uma fórmula de abrigar o Direito também sob uma perspectiva universal e científica, com utilização nos mesmos moldes a todas as sociedades, comportando seus valores - estes sob outra dimensão -, um espectro fora da ciência jurídica, sem despi-los de sua importância ou refutar os ideais kantianos.

Kant buscava a coesão e universalidade em todas as dimensôes; Kelsen aparentemente enxergava a impossibilidade destes elementos presentes com estes matizes e criou uma nova dimensão, mais próxima do possível, positiva, para que nela, essencialmente e unicamente jurídica, se materializasse a coesão e universalidade na regulamentação da conduta humana que se manifestaria formalmente e validamente em uma decisão judicial, sendo desimportante os valores nela contidos desde que congruentes com a lei.

As duas proposiçôes sofrem críticas e padecem de soluçóes incontestes para serem sufragadas de forma unânime, mas Kelsen parece ter vislumbrando com maior acuidade a dimensão da contradição humana neste estágio de desenvolvimento, bem como os reflexos e as características dos valores comunitários cultivados e sua ligação com a política e o poder, bem como sua relatividade, buscando uma neutralidade científica na construção da estrutura jurídica que permitisse a canalização destes valores pela norma positivada com pretensão de clareza e segurança, sem rechaçar a relevância de valores altaneiros.

Se em vários pontos podemos abalar a sustentação da teoria kelseniana, aparentemente ao menos em sua interpretação da Moral e Justiça positivada - ou jurídica -, traduzindo-se em legitimação formal a partir da relatividade daquelas, mostra-se atual e claramente difundida pelo globo, dotada de escorreita precisão metodológica e filosófica.

\section{REFERÊNCIAS}

ALEXY, Robert. Teoria da argumentação jurídica: a teoria do discurso racional como teoria da fundamentação jurídica. Trad. Zilda Hutchinson Schild Silva. 3. ed. Rio de Janeiro: Forense, 2013.

ARON, Raymond. As etapas do pensamento sociológico. Trad. Sérgio Bath. 7. ed. São Paulo: Martins Fontes, 2008.

BACON, Francis. Ensaios sobre moral e politica. Trad. Edson Bini. Bauru: Edipro, 2001. 
BARROSO, Luis Roberto. Judicialização, ativismo judicial e legitimidade democrática. 2009. P. 1-23. Disponível em: <www.direitofranca.br/direitonovo/FKCEimagens/file/ArtigoBarroso_para_Selecao.pdf>. Acesso em: 31 out. 2011.

. Neoconstitucionalismo e constitucionalização do direito: o triunfo tardio do direito constitucional no Brasil. Boletim de Direito Administrativo [recurso eletrônico], São Paulo, v. 23, n. 1, p. 20-49, jan. 2007. Disponível em: <http://dspace/xmlui/bitstream/item/7404/ geicIC_FRM_0000_pdf.pdf?sequence=1>. Acesso em: $1^{\circ}$ jun. 2015.

- O novo direito constitucional brasileiro: contribuiçôes para a construção teórica e prática da jurisdição constitucional no Brasil. 2 ed. Belo Horizonte: Fórum, 2013.

BASTOS, Celso Ribeiro. Hermenêutica e interpretação constitucional-pressupostos hermenêutico-constitucionais. 3. ed. São Paulo: Celso Bastos, 2002.

BAUMAN, Zygmunt. Legisladores e intérpretes: sobre modernidade, pós-modernidade e intelectuais. Trad. Renato Aguiar. Rio de Janeiro: Zahar, 2010a.

. Aprendendo a pensar com a sociologia. Trad. Alexandre Werneck. Rio de Janeiro: Zahar, 2010b.

BECCARIA, Cesare. Dos delitos e das penas. Trad. Torrieri Guimarães. 7. ed. São Paulo: Martin Claret, 2014.

BENGOETXEA, Joxerramon. Una defensa del consecuencialismo en el derecho. Disponível em: <http://scholar.google.com.br/scholar?q=UNA+DEFENSA+DEL+CONSECUE $\mathrm{NCIALISMO}+\mathrm{EN}+\mathrm{EL}+\mathrm{DERECHO}+$ Joxerramon + Bengoetxea\&btnG $=\& \mathrm{hl}=\mathrm{pt}-\mathrm{BR} \&$ as_sdt=0\%2C5.>. Acesso em: $1^{\circ}$ jun. 2015.

BOBBIO, Norberto. A era dos direitos. Trad. Carlos Nelson Coutinho. Apres. Celso Lafer. Rio de Janeiro: Elsevier, 2004.

CARNIO, Henrique Garbelllini. Direito e Antropologia: reflexóes sobre a origem do Direito a partir de Kelsen e Nietzsche. São Paulo: Saraiva, 2013.

CHOMSKY, Noam. Natureza humana: justiça vs. poder: o debate entre Chomsky e Foucault. Edit. Fons Elders. Trad. Fernando Santos. São Paulo: Editora WMF Martins Fontes, 2014. COMPARATO, Fábio Konder. Ética: direito, moral e religião no mundo moderno. São Paulo: Companhia das Letras, 2006.

DIAS, Reinaldo. Sociologia do direito: a abordagem do fenômeno jurídico como fato social. 2. ed. São Paulo: Atlas, 2014.

DIMOULIS, Dimitri; MARTINS, Leonardo. Teoria geral dos direitos fundamentais. São Paulo: Revista dos Tribunais, 2007. 
DIMOULIS, Dimitri; MARTINS, Leonardo. Neoconstitucionalismo e moralismo jurídico. Disponível em: <http://www.academia.edu/1615334/Neoconstitucionalismo_e_moralismo_juC3\%Addic>. Acesso em: $1^{\circ}$ jun. 2015.

DWORKIN, Ronald. O império do direito. Trad. Jeferson Luiz Camargo. Rev. Téc. Gildo Sá Leitão Rios. 3. ed. São Paulo: Martins Fontes - selo Martins, 2014. (Justiça e direito).

FERREIRA, Delson. Manual de sociologia: dos clássicos à sociedade da informação. 2. ed. São Paulo: Atlas, 2012.

GRAU, Eros Roberto. Por que tenho medo dos juizes: a interpretação do direito e os princípios. 6. ed. São Paulo: Malheiros; Método, 2013.

GUERRA FILHO, Willis Santiago; CARNIO, Henrique Garbellini. Teoria politica do direito: a expansão política do direito. 2. ed. rev., atual. e ampl. São Paulo: Editora Revista dos Tribunais, 2013.

. Introdução à sociologia do direito. São Paulo: Editora Revista dos Tribunais, 2016.

HERANI, Renato Gugliano. Controle de constitucionalidade das leis pré-constitucionais. Rio de Janeiro; São Paulo: Forense; Método, 2010.

KANT, Immanuel. Critica da razão pura. Trad. J. Rodrigues de Merege. Rio de Janeiro: Nova Fronteira, 2014.

KELSEN, Hans. Teoria pura do direito. Trad. J. Cretella Jr. e Agnes Cretella. 9. ed. rev. São Paulo: Editora Revista dos Tribunais, 2013. (RT - textos fundamentais; 5).

. Teoria pura do direito. Trad. João Baptista Machado. 6 ed. São Paulo: Martins Fontes, 1998. (Ensino Superior).

LUNARDI, Soraya Gasparetto. Modulação temporal dos efeitos no processo de controle de constitucionalidade e influência de argumentos econômicos. Revista Brasileira de Estudos Constitucionais, Belo Horizonte, v. 3, n. 9, p. 209-227, jan./mar. 2009. Disponível em: <http://dspace/xmlui/bitstream/item/6284/Biblioteca\%20Digital\%20-\%20Editora\%20 F\%C3\%B3rum.pdf?sequence=1>. Acesso em: 1\% jun. 2015.

MACHADO NETO, Antônio Luis. 1930-1977. Sociologia jurídica. 6. ed. São Paulo: Saraiva, 1987.

MULLER, Friedrich. Tesis acerca de la estructura de las normas jurídicas. Revista española de derecho constitucional. Madrid, n. 27, p. 111-126, 1989. Disponível em: <http://dialnet. unirioja.es/servlet/autor?codigo=77386>. Acesso em: $1^{\circ}$ jun. 2015.

. Juristische Methodik. 5. ed. Berlin: Duncker \& Humblot, 1993. 255 p. 
NIETZSCHE, Friedrich Wilhelm. Genealogia da moral: uma polêmica. Trad. notas e posfácio de Paulo César de Souza. São Paulo: Companhia das Letras, 2009.

- Além do bem e do mal: prelúdio a uma filosofia do futuro. Trad. notas e posfácio de Paulo César de Souza. 1 ed. São Paulo: Companhia das Letras, 2005.

Crepúsculo dos ídolos, ou, como se filosofa com o martelo. Trad. apres. e notas de Renato Zwick. Porto Alegre, RS: L\&PM, 2015.

. Assim falava Zaratrusta: livro para toda gente e para ninguém. Ap. Elisabeth Foster Nitzsche. Trad. José Mendes de Souza. Pref. Geir Campos. Ed. especial. Rio de Janeiro: Nova Fronteira, 2012. (Saraiva de Bolso).

PAULA, Gil César Costa de. Teoria geral do estado: textos para uma abordagem crítica. Goiânia: Ed. Vieira, 2010.

PEGORARO, Lucio. La circulación, la recepción y la hibricación de los modelos de justicia constitucional. Disponível em: <www.cepc.gob.es/publicaciones/revistas/revistaselectronica sR=8\&IDN=398\&IDA=1432>. Acesso em: $1^{\circ}$ jun. 2015.

REVORIO, Francisco Javier Díaz. Valores superiores e interpretación constitucional. Colección: Estudios Constitucionales. Madrid: Centro de Estudios Políticos y Constitucionales, 1997. SCHOPENHAUER, Arthur. As dores do mundo: o amor - a morte - a arte - a moral - a religião - a política - o homem e a sociedade. Trad. José Souza de Oliveira. São Paulo: Edipro, 2014. (Clássicos Edipro).

SCURO NETO, Pedro. Sociologia geral e jurídica: introdução ao estudo do direito, instituições jurídicas, evolução e controle social. 7. ed. São Paulo: Saraiva; Zahar, 2010.

SPECTOR, Céline. Vocabulário de Montesquieu. Trad. Cláudia Berliner. São Paulo: WMF Martins Fontes, 2011.

TAVARES, André Ramos. A constituição é um documento valorativo? Revista Brasileira de Direito Constitucional. São Paulo, n. 9, p. 337-348, jan./jun. 2007.

. Paradigmas do judicialismo constitucional. São Paulo: Malheiros; Saraiva, 2012.

TZU, Sun. A arte da guerra. Trad. Elvira Vigna. [Ed. especial]. Rio de Janeiro: Nova Fronteira, 2011. (Saraiva de bolso).

Recebido em: 8/7/2016

Revisóes requeridas em: 24/7/2016

Aceito em: 3/8/2016 